\title{
Brainstorming: Thinking - Problem Solving Strategy
}

\author{
Ms. Agnes Monica .V
}

Post graduated in Psychiatric Mental Health Nursing currently employed in King Saud Bin Abdulaziz. University for Health Sciences Riyadh, Kingdom of Saudi Arabia.

\section{ABSTRACT}

Brainstorming is a popular tool that helps you generate creative answers to a problem. It is mainly useful when you want to break out of stale, established patterns of thinking, so that you can develop new ways of looking at things. The aforementioned also helps you overcome many of the concerns that can make collection problemsolving a sterile and substandard process. Though group brainstorming is often more effective at generating ideas than normal group problem-solving, study after study has revealed that when individuals brainstorm on their own, they come up with more ideas and often better quality ideas than groups of people who brainstorm together.

I.

\section{RODUCTION}

Brainstorming is a group creativity technique by which efforts are made to find a conclusion for a specific problem by gathering a list of ideas spontaneously contributed by its members. The term was popularized by Alex Faickney Osborn in the 1953 book Applied Imagination. Brainstorming is a method for developing creative resolutions to problems. Brainstorming works by focusing on a problem, and then deliberately coming up with as many solutions as possible and by assertive the thoughts as far as possible. One of the causes it is so effective is that the brainstormers not only come up with new ideas in a session, but also spark off from associations with other people's ideas by developing and refining them. Brainstorming combines a relaxed, informal approach to problemsolving with lateral thinking. It asks that people come up with ideas and thoughts that can at first seem to be a bit unwise. The impression here is that some of these ideas can be crafted into original, creative solutions to the problem you're trying to solve, while others can trigger still more ideas. This tactic aims to get people unstuck, by" (Osborn, 1963).

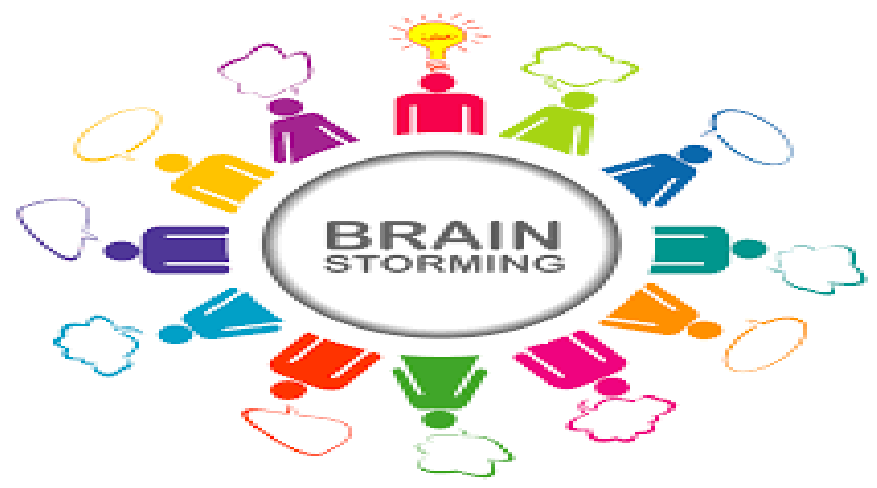

\section{Group Brainstorming}

When it works, group brainstorming can be very effective for bringing the full experience and creativity of all members of the group to bear on an issue. When individual group members get trapped with an idea, another member's creativity and experience can take the idea to the next stage. Group brainstorming can therefore develop ideas in more depth than individual brainstorming. Additional advantage of group brainstorming is that it helps everyone involved to feel that they've contributed to the end solution, and it reminds people that other people have creative ideas to offer.

\section{Using the Tool}

The results will be better when combining individual and group brainstorming, and by managing the process carefully and according to the "rules" below. By this way, we get people to focus on the issue without interruption (this comes from having everyone in a dedicated group meeting), maximize the number of ideas we make, 


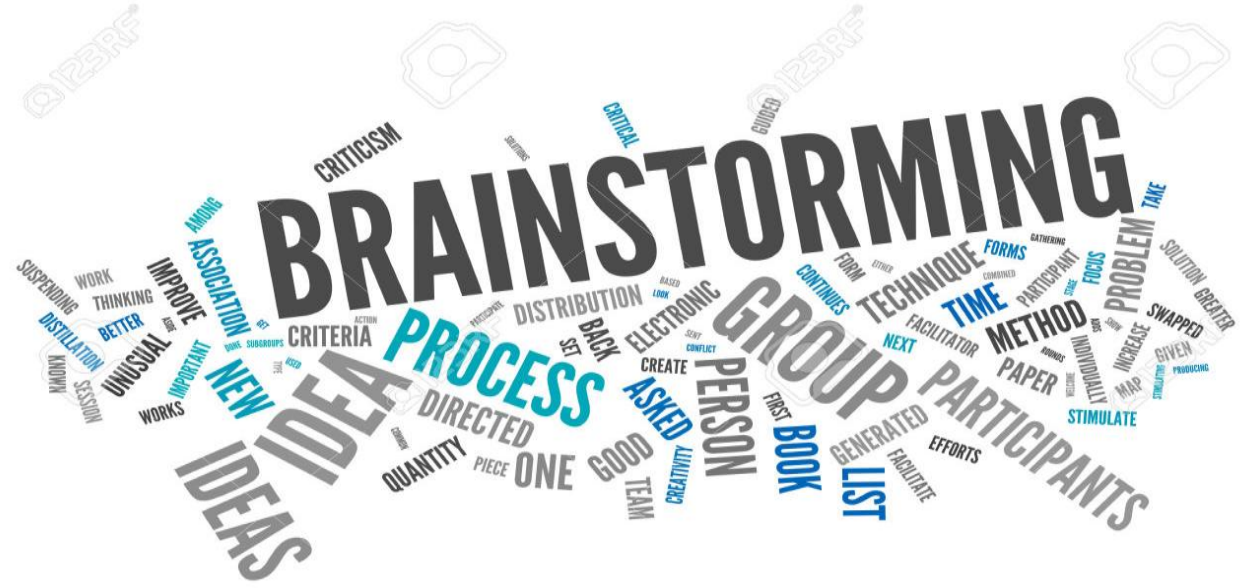

\section{Effective steps in Brainstorming}

Find a comfortable meeting environment, and set it up ready for the session.<smiles>C1CCCCC1</smiles>

Gather the participants from as wide a range of disciplines with as broad a range of experience as possible. This brings many more creative ideas to the session.<smiles>C1CCCCC1</smiles>

Set down a brief description of the problem the leader should take control of the session, primarily defining the problem to be solved with any criteria that must be met, and then keeping the session on course.

Appoint one person to record the ideas that come from the session which should be noted in a format than everyone can see and refer to. Record ideas on flip charts, whiteboards, or computers with data projectors.<smiles>C1CCCC1</smiles>

Use the description to get everyone's mind clear of what the problem is and post it where it can be seen. This helps in keeping the group dedicated.

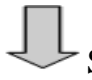

Support an enthusiastic, uncritical attitude among brainstormers and encourage participation by all members of the team.<smiles>C1C[In]C[I-]C1</smiles>

Consider an appropriate warm-up exercise or ice-breaker.<smiles>C1CCCC1</smiles>

Define the problem we want solved clearly, and lay out any criteria to be met. Make it clear that that the objective of the meeting is to generate as many ideas as possible.
1 Give people plenty of time on their own at the start of the session to produce as many ideas as possible.

$\square$ Enquire people to give their ideas, making sure that you give everyone a fair opportunity to contribute.

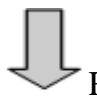

Reassure people to develop other people's ideas, or to use other ideas to create new ones.

$\square$ Ensure that no one criticizes or evaluates ideas during the session. Criticism introduces an element of risk for group members when putting forward an idea.<smiles>C1CCCCC1</smiles>

Write down all the solutions that come to mind (even ribald ones). Do NOT interpret the idea, however you may rework the wording for clarity's sake.

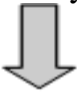

Encourage them to come up with as many ideas as possible.

$\square$

Do NOT evaluate ideas until the session moves to the evaluation phase. When the brainstorming session has been completed, the results of the session can be analyzed and the best solutions can be explored either using further brainstorming or more conventional solutions.

$\square$

Do NOT censor any solution, no matter how trivial it sounds. The meaningless ones will often lead to creative ones - the idea is to open 
up as many possibilities as possible, and break down preconceptions about the limits of the problem.

Once all the solutions have been written down, evaluate the list to determine the best action to correct the problem.

Approaches used to increase the number of ideas

- The Stepladder Technique - This improves the contribution of quieter members of the group, by introducing ideas one person at a time.

- Brain writing - Brain writing uses a written approach to brainstorming to generate and develop ideas. This helps to get ideas from all individuals, and develop these ideas in depth.

Brain-netting - This is similar to Brain writing, but uses an electronic document stored on a central server.

- The Crawford's Slip Approach - The Crawford's Slip Approach helps to get plenty of ideas from all participants in the session, and gives a view of the popularity of each idea.

\section{Four basic rules in brainstorming}

According to Osborn, 1963 there are four rules intended to reduce social inhibitions among team members, stimulate idea generation, and increase overall creativity:

- No criticism: Criticism of ideas are withheld during the brainstorming session as the purpose is on generating varied and unusual ideals and extending or adding to these ideas. Criticism is reserved for the evaluation stage of the process. This allows the members to feel comfortable with the idea of generating unusual ideas.

- Welcome unusual ideas: Unusual ideas are welcomed as it is normally easier to "broken down" than to "broken up" as new ways of thinking and looking at the world may provide better solutions.

- Quantity Wanted: The better the number of ideas generated, the larger the chance of producing a radical and effective solution.

- Combine and improve ideas: Not only are a variety of ideals wanted, but also ways to combine ideas in order to make them better.

The techniques

- Reverse Brainstorming - This is useful for improving a product or service.
- Star bursting - Star bursting helps you brainstorm the questions you need to ask to evaluate a proposal.

- Charette Procedure - This procedure helps you brainstorm effectively with large groups of people. (Conventional brainstorming is cumbersome and increasingly ineffective when more than 10 to 12 people are involved.)

- Round-Robin Brainstorming - This technique helps you ensure that people will contribute great ideas without being influenced by others in the group.

- Role storming - This method encourages group members to take on other people's identities while brainstorming. This reduces the inhibitions that many people feel when sharing their ideas with a group.

\section{Other techniques}

\section{- Nominal group technique}

The nominal group technique is a type of brainstorming that encourages all participants to have an equal say in the process. It is also used to generate a ranked list of ideas. Participants are asked to write their ideas anonymously. Then the moderator collects the ideas and the group votes on each idea. The vote can be as simple as a show of hands in favor of a given idea. This process is called distillation.

After distillation, the top ranked ideas may be sent back to the group or to subgroups for further brainstorming. For example, one group may work on the color required in a product. Another group may work on the size, and so forth. Each group will come back to the whole group for ranking the listed ideas. Sometimes ideas that were previously dropped may be brought forward again once the group has re-evaluated the ideas.

It is important that the facilitator be trained in this process before attempting to facilitate this technique. The group should be primed and encouraged to embrace the process. Like all team efforts, it may take a few practice sessions to train the team in the method before tackling the important ideas.

\section{- Group passing technique}

Each person in a circular group writes down one idea, and then passes the piece of paper to the next person, who adds some thoughts. This continues until everybody gets his or her original piece of paper back. By this time, it is likely that the group will have extensively elaborated on each idea.

Team idea mapping method his method of brainstorming works by the method of association. It may improve collaboration and 
increase the quantity of ideas, and is designed so that all attendees participate and no ideas are rejected. The process begins with a well-defined topic. Each participant brainstorms individually, then all the ideas are merged onto one large idea map. During this consolidation phase, participants may discover a common understanding of the issues as they share the meanings behind their ideas. During this sharing, new ideas may arise by the association, and they are added to the map as well. Once all the ideas are captured, the group can prioritize and/or take action.

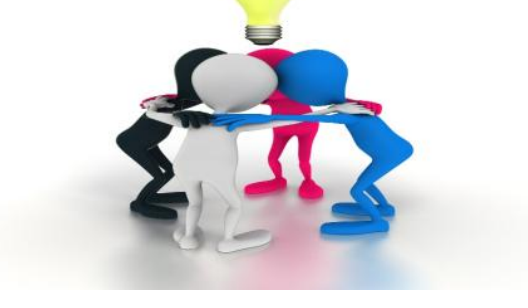

\section{- Electronic brainstorming}

It is a computerized version of the manual brainstorming technique typically supported by an electronic meeting system (EMS) but simpler forms can also be done via email and may be browser based, or use peer-to-peer software. ${ }^{[9]}$

\section{- Directed brainstorming}

Directed brainstorming is a variation of electronic brainstorming (described above). It can be done manually or with computers. In directed brainstorming, each participant is given one sheet of paper (or electronic form) and told the brainstorming question. They are asked to produce one response and stop, then all of the papers (or forms) are randomly swapped among the participants. The participants are asked to look at the idea they received and to create a new idea that improves on that idea based on the initial criteria. The forms are then swapped again and respondents are asked to improve upon the ideas, and the process is repeated for three or more rounds.

\section{- $\quad$ Guided brainstorming}

A guided brainstorming session is time set aside to brainstorm either individually or as a collective group about a particular subject under the constraints of perspective and time. This type of brainstorming removes all cause for conflict and constrains conversations while stimulating critical and creative thinking in an engaging, balanced environment. Innovative ideas consistently emerge.

Participants are asked to adopt different mindsets for pre-defined period of time while contributing their ideas to a central mind map drawn by a pre-appointed scribe. Having examined a multi-perspective point of view, participants seemingly see the simple solutions that collectively create greater growth. Action is assigned individually. Following a guided brainstorming session participants emerge with ideas ranked for further brainstorming, research and questions remaining unanswered and a prioritized, assigned, actionable list that leaves everyone with a clear understanding of what needs to happen next and the ability to visualize the combined future focus and greater goals of the group.

www.theglobalbrainstorm.com is currently Beta testing the mass use of this way of working and will publish results. 12 months of field trials report a consistent time saving of $75 \%$ (reducing 1 hour brainstorming sessions to 15 minutes), increased levels of contribution, productivity and motivation and a frequent emergence of innovative ideas.

\section{- Individual brainstorming}

"Individual brainstorming" is the use of brainstorming in solitary. It typically includes such techniques as free writing, free speaking, word association, and drawing a mind map, which is a visual note taking technique in which people diagram their thoughts. Individual brainstorming is a useful method in creative writing

\section{- Question brainstorming}

This process involves brainstorming the questions, rather than trying to come up with immediate answers and short term solutions. Theoretically, this technique should not inhibit participation as there is no need to provide solutions. The answers to the questions form the framework for constructing future action plans.

\section{REFERENCES}

[1]. Osborn, A.F. (1963) Applied imagination: Principles and procedures of creative problem solving (Third Revised Edition). New York, NY: Charles Scribner's Sons.

[2]. Productivity Loss in Idea-Generating Groups: Tracking Down the Blocking Effect". Journal of Personality and Social Psychology61 (3): 392-403. 1991.

[3]. Productivity Loss in Brainstorming Groups: Toward the Solution of a Riddle". Journal of Personality and Social Psychology53: 497509. 1987.

[4]. Brown, V; Paulus, P. B (1996). "A simple dynamic model of social factors in group brainstorming". Small Group Research27: 91-114.

[5]. Stroebe, W.; Diehl, M. \&Abakoumkin, G. (1992). "The illusion of group effectivity". 
Personality and Social Psychology Bulletin18 (5): 643-650.

[6]. Paulus, P. B.; Dzindolet, M. T., Poletes, G.,Camacho, L. M. (1993). "Perception of performance in group brainstorming: The illusion of group productivity". Journal of Personality and Social Psychology64 (4): 575-586.

[7]. Toubia, Olivier. "Idea Generation, Creativity, and Incentives". Marketing Science. $\quad$ http://www.amsinc.com/pdf/Toubia_MarketingScience.pdf. Retrieved 28 April 2011.

[8]. http://litemind.com/what-is-mind-mapping/

\section{AUTHORS PROFILE}

Ms. Agnes Monica .V post graduated in Psychiatric

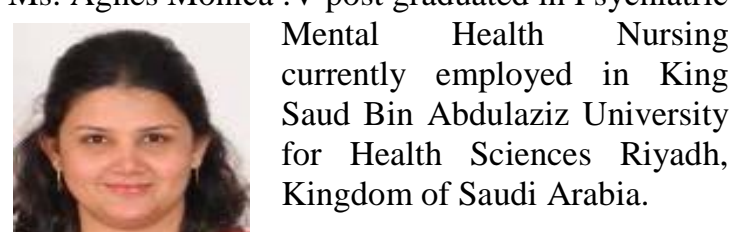

